\title{
Acoustic data collected during and between bottom trawl stations: consistency and common trends
}

\author{
Nicolas Bez ${ }^{1, *}$, David Reid ${ }^{2}$, Suzanna Neville ${ }^{3}$, Yves Vérin ${ }^{4}$, \\ Vidar Hjellvik ${ }^{5}$ and Hans D. Gerritsen ${ }^{6}$
}

(1) Ecole des mines, Géostatistique, Fontainebleau, France. (Present address : IRD, Rue Jean Monnet, BP171, 34203 Sète, France)

(2) FRS-MLA, PO Box 101, Victoria road, Torry, Aberdeen,AB11 9DB UK

(3) CEFAS, Lowestoft Laboratory, Pakefield Road, Lowestoft, Suffolk, NR33 OHT, UK

(4) IFREMER, 150 Quai Gambetta, 62321 Boulogne sur Mer, France

(5) IMR PO BOX 1870 N-5024 Bergen, Norway

(6) QUB / DARDNI, Newforge Lane, Belfast, BT9 5PX, Northern Ireland, UK. (Present address: Marine Institute, Rinville, Oranmore, Galway, Ireland)

*: Corresponding author : nicolas.bez@ird.fr

\begin{abstract}
Acoustic data are often collected during bottom trawl surveys. Their use can potentially improve the precision and accuracy of fish abundance estimates if acoustic data collected between trawl stations are consistent with those collected during trawling operations. This question is addressed here through the analysis of 20 bottom trawl surveys (three survey areas and five different survey series) with coincident acoustic measurements during and between trawl stations. Firstly, onstation and underway acoustic data were compared using statistics computed globally over each survey (average vertical profiles, global indices of collocations, and spatial structures) for various combinations of depth layers. Secondly, we focussed on underway acoustic data recorded in the vicinity of stations, distinguishing between data recorded before and after the tows. On-station and underway acoustic data were highly consistent, and no systematic perturbation of the acoustic sign due to the presence of the gear a few hundred metres behind the vessel was observed.
\end{abstract}

Résumé : On récolte souvent des données acoustiques durant les inventaires faits au chalut de fond. Leur utilisation peut potentiellement améliorer la précision et la justesse des estimations d'abondance des poissons, si les données acoustiques récoltées entre les stations de chalutage sont compatibles avec celles récoltées durant les opérations de pêche. Nous examinons la question en analysant 20 inventaires faits au chalut de fond (trois zones d'inventaire et cinq séries différentes d'inventaires) pour lesquels il existe des mesures acoustiques coïncidentes obtenues dans et entre les stations de chalutage. Nous avons d'abord comparé les données acoustiques obtenues en route et dans les stations à l'aide de statistiques calculées globalement pour chaque inventaire (profils verticaux moyens, indices globaux de collocation et structures spatiales) selon diverses combinaisons de couches de profondeur. Ensuite, nous nous sommes intéressés aux données acoustiques obtenues en route près des stations, en distinguant entre les données enregistrées avant et après le chalutage. Il existe un excellent accord entre les données acoustiques obtenues dans les stations et celles enregistrées en route; on n'observe pas de perturbation systématique du signal acoustique due à la présence des engins de pêche à quelques centaines de mètres derrière le navire. 


\section{Abstract}

20 Acoustic data are often collected during bottom trawl surveys. Their use can

21 potentially improve the precision and accuracy of fish abundance estimates if acoustic

22 data collected between trawl stations are consistent with those collected during trawling

23 operations. This question is addressed by the current paper through the analysis of twenty

24 bottom trawl surveys (three survey areas and five different survey series) with coincident

25 acoustic measurements during and between trawl stations. Firstly, on-station and

26 underway acoustic data were compared using statistics computed globally over each

27 survey (average vertical profiles, global indices of collocations and spatial structures) for

28 various combinations of depth layers. Secondly, we focussed on underway acoustic data

29 recorded in the vicinity of stations, distinguishing between data recorded before and after

30 the tows.

31 On station and underway acoustic data were highly consistent and no systematic

32 perturbation of the acoustic sign due to the presence of the gear few hundreds meters

33 behind the vessel was observed.

\section{$34 \quad$ Key words}

35 Bottom trawl, acoustic, gear perturbation

\section{Introduction}

37 Bottom trawl surveys are one of the main survey methods used in the assessment

38 of demersal fish stocks around the world (Gunderson 1993). It has recently become

39 possible to carry out combined acoustic and bottom trawl surveys (e.g., in the Barents

40 Sea, Aglen and Nakken 1997; Korsbrekke et al. 2001) or to collect acoustic and trawl

41 data while carrying out a bottom trawl survey (Cachera et al. 1999; Krieger et al. 2001). 
42 In some cases, such as Barents Sea cod (Gadus morhua L., Korsbrekke et al. 2001), the

43 acoustic data are used to generate a secondary abundance index from the survey in

44 addition to a trawl catch-rate index. Acoustic observations can also be used to gain

45 additional information on fish availability and distribution away from the trawl station in

46 order to improve the precision and accuracy of the trawl-based estimate. These two

47 approaches were the basis for the EU funded (Framework Programme 5) project

48 CATEFA (Combining Acoustic and Trawl data for Estimating Fish Abundance).

49 Two hypotheses need to be confirmed to allow this combination of acoustic and

50 trawl survey data. The first is that the fishing gear and the acoustic devices are measuring

51 the same thing. If true it would become possible to derive a relationship between trawl

52 catch and acoustic observations (Krieger et al. 2001; Hjellvik et al. 2003). The second is

53 that acoustic data collected away from the trawl stations is consistent with that collected

54 during the trawling operations. The present paper deals with the second hypothesis.

55 There is considerable evidence that fish engage in avoidance behaviour to the 56 trawl/vessel combination (Godø et al. 1999; Michalsen 1999; Handegard et al. 2003;

57 Kloser and Horne 2003). Vessel speed is generally low during trawling (e.g. around 3

58 knots) and, a large and noisy net is being towed. Away from the trawl stations, the survey

59 vessel moves much faster (usually over 10 knots) and without a net. The evidence is

60 mixed as to whether fish also engage in avoidance behaviour under this scenario (Mitson

61 and Knudsen 2003; Fréon and Misund 1999; Fernandes et al. 2000). Different avoidance

62 reactions, and hence availability to the echosounder, could have a significant impact on

63 what is seen on the echogram. In order to use the acoustic data between trawl stations for

64 the purpose of improving trawl survey estimates or of combining the data, we must be 
65 sure that the echosounder is seeing the same component of a population during trawling

66 as it does while running between stations. This study uses data from a number of different

67 trawl surveys in the North, Irish and Barents Seas (Fig. 1a). It examines the relationship

68 between on-station and between-station acoustic data at both the local level (i.e.,

69 immediately adjacent to the trawl station) and more globally for each survey.

\section{Material and methods}

\section{Surveys and data preparation}

72 Bottom trawl data with coincident acoustic measurements from three survey areas 73 and five different survey series were used in this analysis (Table 1).

74 The International Council for the Exploration of the Sea (ICES) co-ordinates the 75 International Bottom Trawl Surveys (IBTS) in the North Sea. These surveys follow a 76 random design, stratified by ICES rectangle (Fig. 1b). Trawl and acoustic data are only

77 collected during daylight hours. The surveys used in this study were those carried out by

78 the Centre for Environment Fisheries and Aquaculture Science (Cefas) - Lowestoft 79 (2000, 2001 and 2002), the Fisheries Research Services (FRS) - Aberdeen (1999, 2000 80 and 2002) and the Institut Français de Recherche pour l'Exploitation de la Mer (Ifremer)

81 - Boulogne (2002 and 2003). Each survey comprises between 60 and 80 stations. The

82 North Sea data had the most skewed distributions with many low values and a few

83 extremely high values. In the case of the French data, $65 \%$ of the total back-scattering 84 energy on-station was concentrated in $3 \%$ of the stations.

85 The Northern Irish Bottom Trawl Surveys (NIBTS) in the Irish Sea. These 86 surveys are mostly small (35 to 45 stations) and follow a random sampling design 87 stratified by depth and substrate (Fig. 1c). Depth varied between 23 and $102 \mathrm{~m}$. Four 
88 surveys carried out by Dardni (Department of Agriculture and Rural Development,

89 Northern Ireland) Belfast were available: autumn 1997, spring 2000, autumn 2001 and

90 spring 2002. These surveys tend to encounter much more pelagic fish like herring

91 (Clupea harengus) and sprat (Sprattus sprattus) than in the North Sea or Barents Sea 92 surveys.

93 The combined acoustic and bottom trawl surveys for cod (Gadus morhua) and 94 haddock Melanogrammus aeglefinus) in the Barents Sea - are conducted by the Institute 95 of Marine Research (IMR) Bergen. Sampling follows a regular grid with a haul every 20 96 n.mi. (Fig. 1d). The number of hauls varied between 200 and 300. Surveys were available $97 \quad$ from 1997 to 2002.

98 Simrad EK500 scientific echosounders were used for all surveys, with at least a $9938 \mathrm{kHz}$ split-beam transducer. The echo-sounder angle was of $7^{\circ}$ and its pulse duration 100 was of $1 \mathrm{~ms}$. For this frequency, the efficiency of the TVG is 580 meters (Diner \& 101 Marchand, 1995). Since the maximum depth encountered in the different surveys used in 102 this study was between 23 meters (Irish Sea) and 540 meters (Barents Sea), the 103 propagation loss was not a problem. The acoustic back-scattering energies were 104 converted to Nautical Area Scattering Coefficient (NASC; MacLennan et al. 2002) and 105 expressed in $\mathrm{m}^{2} \cdot n \cdot \mathrm{mi}^{-2}$. The integration threshold was set at $-70 \mathrm{~dB}$ NASC values were 106 available from trawl stations and between trawl stations. For the on-station NASC, 107 integration was carried out for the whole trawling period. In general, the tow length is 108 fixed within each survey series. NASC values between trawl stations were available at 109 fixed Elementary Sampling Distance Units (ESDU) which differed by survey series: 0.1 
110 n.mi. for IFREMER data, 1 n.mi. for IMR data, and 0.5 n.mi. for the rest of the datasets

111 (Table 1).

112 Because the ESDUs were smaller than the average tow lengths, between-station

113 NASC values were pooled (regularized) to produce ESDU as close to the average tow

114 lengths as possible for each survey series: $3 \mathrm{n} . \mathrm{mi}$ in the Irish Sea, $1 \mathrm{n} . \mathrm{mi}$. in the Barents

115 Sea, and 2 n.mi in the North Sea.

116 NASC values for each ESDU and trawl station were subdivided into a series of

117 bottom referenced layers (Fig. 2): ten one-meter layers sequentially from the seabed

118 followed by several ten-meters layers. The accuracy of the sounder-detected bottom was

119 verified and corrected where needed. This was achieved using manual or semi-automated

120 procedures in the analysis of the acoustic data. In the latter case, the layer closest to the

121 bottom included a backstep to avoid integrating the seabed. The size of the backstep

122 varied between 10 and $40 \mathrm{~cm}$, depending on the survey series and weather conditions.

123 Acoustic data preparation was carried out using SIMRAD BI500 for the Norwegian data,

124 Movies Plus for the French data and SonarData EchoView 3.1 for all of the other data.

125 Acoustic signals of obvious and well-defined pelagic fish schools were excluded 126 from the analysis.

127 Notations

128 The superscripts indicate whether a parameter refers to on-station $\left({ }^{\circ}\right)$ or between129 station ( ${ }^{b}$ ) data. For instance, the numbers of samples taken on-station and between130 stations are denoted by $N^{o}$ and $N^{b}$. Equations are only given for the on-station data. They 131 are interchangable with between-station data by changing the superscripts. 
$133 i \in\left[1, N^{o}\right]$. The longitude and latitude $\left(x_{i}, y_{i}\right)$ are expressed in decimal degrees. The

134 number and the thickness of the depth layers are denoted by $k$ and $t_{k}$ as follows:

$t_{1}=1 \mathrm{~m} \quad$ if no backstep (manual bottom correction)

$0.6 \mathrm{~m} \leq t_{1} \leq 0.9 \mathrm{~m} \quad$ if backstep (semi-automatic bottom correction)

$138 \quad$ (Eq. 1) $t_{k}=1 \mathrm{~m}$ for $k=2, \ldots, 10$

$t_{k}=10 \mathrm{~m}$ for $k \geq 11$

$146 \quad\left(\right.$ Eq. 2) $s_{V}^{o}(i, k)=\frac{s_{A}^{o}(i, k)}{t_{k}}$

150 Layers were also integrated and grouped into a bottom and a mid-water layer. In 151 the North Sea and Irish Sea, the bottom layer was defined as the bottom $10 \mathrm{~m}$ and the 
152 mid-water layer was the layers between 10 and $40 \mathrm{~m}$ off the bottom (Fig. 2). Because of

153 the high average depth in the Barents Sea area and the large vertical opening of the trawl,

154 the first 40 meters were regarded as the bottom layer and the mid-water layer was

155 between 40 and $100 \mathrm{~m}$ above the bottom:

156

157

158

159

(Eq. 3) $s_{A}^{o}(i, 0-40)=\sum_{k=1}^{13} s_{A}^{o}(i, k) \quad$ and $\quad s_{A}^{o}(i, 40-100)=\sum_{k=14}^{19} s_{A}^{o}(i, k)$

160

161

162

163 The sum over all the layers is denoted by $s_{A}^{o}(i)$.

\section{Global statistics}

165 Vertical profiles

We computed the average vertical profiles for both on-station and between-station

167 NASC for each survey according to:

168

169

170

$171 \quad$ (Eq. 4) $s_{V}^{o}(k)=\frac{\sum_{i=1}^{N^{o}} s_{V}^{o}(i, k)}{N^{o}}$

172 
175 This allows for a visual comparison of vertical fish distributions seen on-station

176 and between stations.

177 Horizontal structures

178 Global index of Collocation

179 The match between the two spatial distributions was evaluated using a Global

180 Index of Collocation (GIC; Bez and Rivoirard 2000). This index is based on the centre of

181 mass and inertia of each spatial distribution. The centre of mass for say the on-station

182 bottom layers in a given area $\left(\mathrm{CoM}_{0-40}^{o}\right)$, was computed as:

183

184

185

186

(Eq. 5) $C o M_{0-40}^{o}=\left(\begin{array}{cc}\sum_{i=1}^{N^{o}} s_{A}^{o}(i, 0-40) \cdot x_{i} & \sum_{i=1}^{N^{o}} s_{A}^{o}(i, 0-40) \cdot y_{i} \\ \sum_{i=1}^{N^{o}} s_{A}^{o}(i, 0-40) & \sum_{i=1}^{N^{o}} s_{A}^{o}(i, 0-40)\end{array}\right)$

190 with equal weight given to each sample. The centre of mass is a vector of coordinates

191 giving the mean location of the population in terms of longitude and latitude. The inertia 
195 (Eq. 6) $I_{0-40}^{o}=\frac{\sum_{i=1}^{N^{o}} s_{A}^{o}(i, 0-40) \cdot\left(\left(x_{i}-\operatorname{CoM}_{0-40}^{o}\right)^{2}+\left(y_{i}-\operatorname{CoM}_{0-40}^{o}\right)^{2}\right)}{\sum_{i=1}^{N^{o}} s_{A}^{o}(i, 0-40)}$

199 is expressed in surface units (typically square nautical miles) and quantifies the spatial 200 dispersal of the population. The Global Index of Collocation (GIC) is given by:

204 (Eq. 7) $G_{0-40}=1-\frac{\left(\operatorname{CoM}_{0-40}^{o}-\operatorname{CoM}_{0-40}^{b}\right)^{2}}{\left(\operatorname{CoM}_{0-40}^{o}-\operatorname{CoM}_{0-40}^{b}\right)^{2}+I_{0-40}^{o}+I_{0-40}^{b}}$

208 It measures the spatial overlap between the on station and between-station populations 209 and ranges from 1 for complete spatial overlap between the two populations to 0 when

210 the two are distinct. Numerically, it decreases quickly with decreasing spatial overlap.

211 This index is analogous to an analysis of variance type of criteria as it compares the mean 212 (square) distance between the centroïds of the two populations, and the mean (square) 213 distance between two individuals taken at random and independently from any of the two 214 populations (Bez, in press). 
216 Variograms

217 Spatial structures of the vertically integrated NASC values were compared in

218 more detail using variography (e.g. Rivoirard et al. 2000). Because the goal was to

219 compare the spatial structures, and not to estimate biomass, the NASC values were

220 transformed as follows:

223 (Eq. 8) $\log \left(1+s_{A}^{o}(i)\right)$

227 While this non-linear transformation modifies the spatial structure, it does not preclude

228 comparisons of spatial structures from being made. Zero values remain zero after the

229 transformation but differences between large data values are reduced.

230 Because the sample sizes of the two sets were significantly different (a few dozen

231 for on-station data and few hundred for between-station), we did not expect the variances

232 to be equal (especially when dealing with skewed data). We therefore compared

233 normalised variograms, i.e. variograms divided by the empirical variance of input data. In

234 two instances, a poor match was observed between the variograms of on-station and

235 between-station data. The impact of extreme values was then investigated by excluding 236 some of the largest data. 
238 variogram per survey series.

\section{Local statistics : before, during and after trawl}

240 To test for the existence of changes in the acoustic signal due to fish response to

241 trawl gear, we compared records made during trawling with those made just before and

242 after trawling. The objective was to test the null hypothesis (H0) that on-station and

243 nearby between-station NASC values were similar, and more precisely, as similar as two

244 consecutive between-station NASC values that lie outside the stations' areas of influence.

245 A window of the same order of magnitude of the tow durations was chosen to

246 select between-station data located nearby each trawl station (1 n.mi. for Barents Sea

247 surveys, 2 n.mi. for North Sea surveys and 3 n.mi. for Irish Sea surveys). This window

248 was considered to be small enough to provide local statistics but large enough to include

249 a sufficient number of observations.

250 Bottom and mid-water layers were summarized by two statistics: a biomass

251 criteria, i.e. the NASC values integrated over the depth layers and, a measure of vertical

252 distribution, i.e. the altitude of the centre of mass (CoM) of the acoustic energy. The null

253 hypothesis $\mathrm{H} 0$ to be tested, was that these two criteria were equal on average for

254 observations made before, during and after trawling for both the bottom and mid-water 255 layers.

256 Comparisons of observations recorded before, during and after the tows were 257 sensitive to possible mixture of a trawl effect and a distance effect. The objective of the

258 test was thus to disentangle how much the observed differences originated from the

259 distance between the observations and from trawl effects respectively. When the spatial 
260 distribution of fish is such that any two proximate values are naturally similar (strong

261 spatial structure of the study variable), observations made before, during and after a trawl

262 station must be very similar in order for $\mathrm{H} 0$ not to be rejected. On the other hand, if the

263 spatial structure is weak, the average difference between two proximate values is

264 naturally relatively large, and H0 cannot be rejected, even for a relatively large

265 discrepancy between observations made before, during and after trawling. Tests were 266 thus evaluated with regards to the similarity of 1000 randomly selected pairs of

267 successive between-station observations sufficiently far away from trawl stations to

268 preclude a trawl effect. For each survey, the following three differences: during - before;

269 during - after; and random1 - random 2, were thus considered (the first two being

270 positive when the observations recorded during trawling operations were larger). These

271 differences were considered relative to the mean value of the integrated NASC values and

272 the altitude of the centre of mass of the acoustic energy relatively, both parameters were 273 pooled by survey series. Empirical cumulative density functions (cdf) were thus built for

274 each survey series and for bottom and mid-water layers separately.

275 Finally, a paired Student test, robust to departure from normality, was used to test

276 if mean differences were equal to zero. Given H0, a large p-value indicates a high

277 likelihood that observed difference are consistent with a zero mean.

278 Time of day considerations

279 With the exception of the Barents Sea surveys, all surveys are performed during

280 daylight and no impact of the time of the day is expected. In the Barents Sea however,

281 there is ample evidence that vertical zonation of gadoid fish can vary throughout the day

282 or year (Hjellvik et al. 2002). In the present analysis, this would not be expected to have a 
283 major impact. For the pooled analyses, we have combined data for all times of day and

284 equal compensation is expected for both on-station and between-station data as these are

285 homogeneously distributed in time. For the before-during-after studies, each haul is

286 matched to adjacent between-station data taken at same time, thus reducing the impact of

287 diel changes. Finally, surveys are taken at the same time of year (Table 1), thus reducing

288 seasonal effects.

289 Coordinates transformations

290 In order to compute true distances between samples, coordinates were 291 transformed to an orthogonal system. A gnomonic projection with a centre at $\mathrm{N} 72^{\circ} 00$

$292 \mathrm{E} 30^{\circ} 00$ was used for the Barents Sea data. A transformation based on the cosine of the

293 mean latitude of the coordinates was applied to the North Sea and the Irish Sea data

294 separately.

295 Results

296 Vertical profiles

297 There is a clear and consistent trend in the vertical acoustic profiles across surveys 298 and survey series (Fig. 3, 4 and 5). In general, the mean NASC value is highest in the 299 depth layer closest to the bottom, and decreases approximately exponentially over the 300 next five to nine meters. Above this, the mean NASC is either relatively constant or 301 decreases steadily both for on-station and between-station data. For the Irish Sea (Fig. 5)

302 where a lot of the backscatter can be attributed to fish schools, the above-mentioned trend 303 only appears after dense (pelagic) school echo traces have been excluded from the 304 analyses. If these are retained, they result in a more bell-shaped vertical profile with the 305 maximum energy a few meters above the bottom. The match between on station and 
306 between station vertical profiles is nearly perfect for both represented quantiles for the

307 Barents Sea case where the number of stations is large (Fig. 3), but less evident as the

308 number of samples decreases (e.g. Irish Sea; Fig. 5). However, there is no general pattern

309 of on-station or between-station profiles being systematically larger than the other.

310 Similarly, the year-to-year differences in the vertical profiles are consistently reflected in

311 both the on-station and between-station data, regardless of the number of samples.

\section{Global Index of Collocation}

313 The GICs were greater than 0.9 in $75 \%$ of the surveys suggesting a strong overall

314 correspondance in the spatial distributions of NASC values between on-station and

315 between-station data (Fig. 6). The GIC was considerably lower (around 0.6) in only two

316 cases where centres of mass of each distribution was far apart each other compared to the

317 respective dispersion of each population (inertia).

318 No systematic difference in the GIC values was observed between the bottom and mid319 water layers. The mid-water GICs were generally smaller than those of the bottom layers

320 (average GICs of 0.91 and 0.93 respectively) but the difference was not statistically

321 significant (Student's T test: p.value $=0.57$ ).

\section{Variograms}

323 The match between the log-transformed variograms for on-station and between-

324 station data was very good for the Barents Sea surveys (Fig. 7a). For the other survey 325 series (Fig. 7 b-e), a reasonable match was observed. However, in two cases (IBTS from

326 FRS and IFREMER), this was only obtained after respectively $2.5 \%$ and $2 \%$ of the most

327 extreme values were removed. The between-station data allowed resolution of the small-

328 scale spatial structures that are inaccessible with the on-station data alone and would lead 
329 to geostatistical models compounded of a nugget effect that explains around $40 \%$ of the

330 total variability (regardless of survey series) and of a component with autocorrelation

331 limit distance of $200 \mathrm{n} . \mathrm{mi}$ for the Barents Sea surveys, and approximately $50 \mathrm{n}$.mi for the

332 others.

333 Correlation before/during/after trawl

334 Integrated NASC for mid-water layers (Fig. 8a) and for bottom layers (Fig. 8b)

335 All the cumulative histograms of the relative differences were symetrical with a 336 narrow mode around zero indicating that in half of the cases NASC values were larger

337 during trawling than before and after. Empirical c.d.f. were visually highly consistent for

338 a given survey series; the differences between them being larger between than within

339 survey series. The empirical c.d.f. between the quantiles 25 and $75 \%$ were highly

340 consistent. Differences were observed in the distributions' tails only. There was no

341 evidence of the relative differences during - before and during - after having a

342 systematically higher or lower spread than those obtained for randomly selected data. For

343 bottom layers and for all surveys (Fig. 8b), NASC integrations were on average higher

344 during the tow than before or after. However, these means were not significantly different

345 from 0 in most cases (two p-values out of ten below 0.1). Interestingly, the differences

346 between randomly selected off-station data showed the same symetrical and skewed

347 distributions and were considered equal to 0 for all but two cases as well. The picture was

348 somewhat different for the mid-water layers where the NASC values were alternatively

349 smaller and larger during trawling than before or after. This, however, was rarely

350 statistically significant (two p-values out of ten below 0.1). Here again, the average 
351 differences between randomly selected off station data were considered not equal to 0 for

352 two cases.

353 Differences in altitudes of the centre of mass for mid-water layers (Fig. 9a) and for 354 bottom layers (Fig. 9b)

355 Differences in altitudes of the centre of mass from NASC values showed weaker

356 tails and weaker modes than the integrated NASC values did resulting in similar medians

357 and means. For the "bottom" layers (Fig. 2), the majority of the observed differences

358 were less than 1 meter. In only one case (FRS) did the differences during - before and

359 during - after show empirical distributions shifted towards lower values compared to that

360 of the reference situation. Despite the fact that the mean of the latter was significantly

361 different from zero, this was the sole case where we observed a reduction of the mean

362 heigh of the acoustic energy associated to trawling activities. None of the other cases

363 indicated an impact of trawl presence: average differences were alternatively positive or

364 negative, the proportion of p-values smaller than 0.1 was similar for cases with the trawl

365 and without, and the differences between empirical c.d.f. were larger between survey

366 series than within. Interestingly, the during - before and during - after trawling

367 differences observed in the Barents Sea surveys were more concentrated around zero than

368 the differences observed where no trawl was in the water: variations in vertical

369 distributions were thus smoothed when the trawl was present.

\section{Discussion}

371 With the final goal to combine acoustic and catch data, which was not considered 372 in this study, we examined the hypothesis that acoustic data collected away from the 373 trawl stations were consistent with those collected during the trawling operations. Rather 
374 than examine one survey with a particular format, we chose to study a series of different

375 surveys ranging from the Barents Sea to the North and Irish Seas, to attempt to identify

376 broad trends in this type of data. The major differences between the data sets were the

377 numbers of data points available on-station, and the proportion of stations connected with

378 acoustic transects. The Barents Sea surveys included between 200 and 300 trawl stations

379 per survey, whereas in the North and Irish Seas surveys included between 13 and 80

380 stations. IBTS data were only taken in daylight hours, with the last station of the day and

381 the first one of the following day not being connected by acoustic transects. As a

382 consequence, relationships between on-station and between-station observations are

383 likely to be more apparent for the Barents Sea than for any of the other surveys.

384 The first type of analysis was a straightforward global comparison using all the 385 available data, for the pooled NASCs by layers for the on-station and between-station 386 data. The general pattern was broadly consistent across all the surveys. The bulk of the 387 acoustic energy was found in the deepest layers in the water column: the back-scattering 388 energy reduces exponentially as the range from the seabed increases and then stabilises

389 somewhere between $5 \mathrm{~m}$ and $10 \mathrm{~m}$ off the bottom. More importantly, the pattern is 390 similar for both on-station and between-station data. Where differences occurred, they 391 were not systematic as on-station integrated values could be both greater or less than 392 between-station data. Furthermore, where deviations from the general pattern occurred in 393 a particular survey, they were seen in both on-station and between-station data.

394 The Global Indices of Collocation (GICs) confirmed the subjective appraisal of 395 the vertical profiles. To help interpretations, GICs were computed for simulated fish 396 distributions (isotropic Gaussian fish density with fish density being set to zero for 
397 densities below the 5\% quantile). From this simulation, it was concluded that a GIC

398 between 0.6 and 0.8 could be considered as a low value and a threshold of 0.8 might be

399 adopted as a minimum value for a good match (Fig. 10). For the bottom layers, only one

400 survey out of twenty showed a poor match, and this had low station numbers ( $\left.N^{o}=46\right)$.

401 Slightly poorer results were obtained for the mid water layers, with three out of the 402 twenty surveys having low GIC values. NASC values were generally much lower in the 403 mid water layers and also much more variable so this outcome is not surprising.

404 The variograms allowed a more detailed study of the spatial structures associated 405 with the on-station and between-station data. For the Barents Sea data, the relatively high 406 number of stations allowed the generation of good quality variograms for on-station and 407 between-station data. These variograms were highly similar. For the other surveys, the 408 variograms were less well behaved, reflecting the smaller number of samples relative to 409 the sampling area and the large skewness of the data. However, they were also similar, 410 provided that some extreme values were removed in two cases. Variograms were 411 considered relative to their variances; we only compared their shapes. The variance of the 412 between-station data was often larger than the variance of the on-station data because the 413 chances of encountering rare extreme fish concentrations is higher with several thousands 414 samples than with a few dozen or a few hundred samples (Bouleau and Bez, 2005). Still, 415 the strong similarity in the shapes of the variograms, would allow using the spatial 416 structures depicted by the between-station data (rescaled to the on station data variance) 417 to obtain a variogram model usable for the purpose of quantitative estimation. It is worth 418 reiterating here, that the variograms were computed with log-transformed data. This non 419 linear transformation induces bias and the variograms obtained here can not be directly 
420 used for estimation purposes. Both the log-transformation and the selection of a certain

421 quantile (97.5 or 98\%) of the data, aim to reduce the impact of the extreme data. This is

422 not at odds with the fact that most of the total abundance is explained by a very small

423 proportion of data. As a matter of fact, it is usually agreed that fish data behave like log

424 normal variables. When simulating a lognormal variable, the likelihood of getting an

425 extreme value increases with the number of samples. Therefore, we could not have

426 expected on-station data to sample the tails of the distributions with the same accuracy as

427 the between-station data, the latter being much more numerous than the former. In

428 addition, the impact of few extreme values on empirical variograms is known to be large

429 and not meaningful for the comparative exercise we did in this study. In other words,

430 what made between-station variograms different from the on-station variograms was only

431 the occurrence of extreme rare data. The bulk of the observations had spatial distributions

432 that matched well.

433 The final step in the analysis, was to examine the relationship between on-station

434 and between-station data in the areas close to each haul. For this comparison we only

435 used the most adjacent between-station data to each haul. However, given the survey

436 protocol, a small but non-zero distance existed between observations made before, during

437 or after trawling. To disentangle how much of the observed differences originated from

438 the distance between the observations and from a possible trawl effect respectively, we

439 bootstrapped between-station data to serve as a reference situation for the comparisons.

440 We found that both before and during trawling data, and during and after trawling data

441 were, with one exception, not more different than two successive randomly selected

442 between-station data (the distributions of their differences are strongly similar). The 
443 statistical approach is designed so that under $\mathrm{H} 0,10 \%$ of the p-value are below 0.1 . In

444 this study, $25 \%$ (10 out of 40 ) of the p-values obtained when testing on station data with

445 adjacent ones were smaller than 0.1 (6 times for the during - before differences and 4

446 times for the during - after differences). Contrary to expectation, this proportion was

$44735 \%$ (7 out of 20) for the so-called reference situations provided by the bootstrapped

448 between-station data. The null hypothesis that the average difference in biomass or in

449 height of the centre of mass for observation made before, during or after trawling was

450 thus acceptable.

451 Most critically for the purposes of this analysis, the inference supported by all the 452 results is that we see similar energy values on-station and between stations, suggesting 453 that we were observing the same fish assemblages in the two situations. However, there is 454 some evidence in the literature of fish reaction to research vessels during trawling (e.g.

455 Godø et al. 1999; Handegard et al. 2003). Reactions can be both vertical, as in diving, or 456 horizontal, as in moving out of or towards the path of the trawl. We shall distinguish 457 between gear and vessel induced reactions. In the Barents Sea for instance, Handegard et 458 al. (2003) showed that the fish present in the 40 first metres above the sea bed, exhibit a 459 slight diving reaction to the vessel passing and a marked horizontal reaction to the warp. 460 Given the mean depths of the study areas, the distances between the acoustic beam 461 beneath the vessel and the trawl, ranged from 100-200 m for Irish Sea and North Sea to 462 more than $500 \mathrm{~m}$ for the Barents Sea (Fig. 11). It is likely though that if the gear does not 463 perturb the fish distribution long in advance (long with regards to the above mentioned 464 distances), on-board mounted echo sounders can only reveal vessel perturbations. In such 
465 a case, the only expected perturbation comes from the vessel which is running both

466 between-station and on-station, the two situations are therefore comparable.

467 We shall also distinguish reactions that lower fish acoustic densities from

468 reactions that increase them. Fish diving would tend to increase fish biomass in the

469 metres above the sea bed. It would also tend to increase tilt angle and hence reduce target

470 strength (MacLennan et al. 1987; McQuinn and Winger 2003; Kloser and Horne 2003).

471 Fish may also move into the acoustic dead zone (Ona and Mitson 1996; Lawson and Rose

472 1999) and be inaccessible to the echosounder. In the present study, the statistically non-

473 significant but systematic stability or increase of NASC value in the "bottom" layers

474 during trawling is associated neither to a corresponding systematic decrease of NASC

475 values in the "mid-water" layers, nor to a change in height of the mean energy in any of

476 the "bottom" or "mid-water" layers. This suggests that none of the above mentioned gear-

477 avoidance behaviours are operating in the study situations and that the area of influence

478 of gear perturbations are, on average, less than the trawl to vessel distances. This does not

479 suggest that trawl perturbations do not exist, but rather that they can not be observed with

480 on-board mounted echo sounders. In particular, gear perturbations were considered to

481 explain the lack of correlations observed between the acoustic signal and catch data or

482 why the highest correlations between acoustic and trawl catches were obtained after

483 acoustic data were integrated over a greater depth than that of the headline height of the

484 trawl (Bouleau et al. 2003, Hjellvik et al. 2003).

485 In conclusion, the acoustic data collected between trawl stations were consistent with the 486 acoustic data collected on stations. Overall, there was good agreement between the two 487 data sets while there were some exceptions in some individual survey series. Poor 
matches could been explained by the sparseness and the skewness of the corresponding

489 data. The Barents Sea case shows what can be achieved for 'bottom' layers with a more

490 substantial data set, where in all cases the on-station and between-station data were

491 consistent for all indicators and methods. In this case, the correlation between catch data

492 and on-station acoustics data is high, making it possible to use between-station acoustics

493 to enhance the quality of trawl survey abundance indices.

494 Acknowledgement

495 This study is part of the EU funded project CATEFA no Q5RS-2001-02038

496 (Combining Acoustic and Trawl data for Estimating Fish Abundance). Authors are also

497 grateful to one of the reviewers who made precise suggestions of modifications to the 498 text.

\section{References}

500 Aglen, A., and Nakken, O. 1997. Improving time series of abundance indices applying 501 new knowledge. Fisheries Research, 30: 17-26.

502 Bez, N.. Spatial statistics for assessing and describing marine resources: the transitive 503 geostatistical approach and the statistics per individual. Journal de la Société Française 504 de Statistique, in press.

505 Bez, N., and Rivoirard, J. 2000. Indices of collocation between populations. In Report of 506 a workshop on the use of Continuous Underway Fish Egg Sampler (CUFES) for mapping 507 spawning habitat of pelagic fish. Edited by D.M. Checkley, J.R. Hunter, L. Motos, and 508 C.D. van der Lingen. GLOBEC Report 14, pp. 1-65.

509 Bouleau, M., Bez, N., Hjellvik, V., Godø, O.R., Reid, D., Beare, D., Greig, T., Amstrong, 510 M., Gerritsen, H., Mackinson, S., Neville, S., van der Kooij, J., Vérin, Y., and Massé, J. 
511 2003. Differences between near bottom biomass spatial structure observed in the Irish

512 Sea, the North Sea and the Barents Sea in recent years. ICES CM 2003/Q:17.

513 Bouleau, M., and Bez, N., 2005. Using a Markov-type model to combine trawl and

514 acoustic data in fish surveys. In: Renard et al. (eds), Geostatistics for environmental

515 applications, Springer, pp 111-123

516 Cachera, S., Massé, J., and Vérin, Y. 1999. How the use of acoustics during bottom trawl

517 surveys may provide more accurate abundance indices: An application to IBTS surveys

518 carried out in the southern North Sea. ICES-CM-1999/J:12

519 Casey, J.M., and Myers, R.A. 1998. Dial variation in trawl catchability: is it as clear as

520 day and night? Canadian Journal of Fisheries and Aquatic Sciences, 5: 2329-2340.

521 Diner, N., and Marchand, P. 1995. Acoustique et pêche maritimes. Ed IFREMER, 522 Plouzané, $147 \mathrm{p}$

523 Fernandes, P.G., Brierley, A.S., Simmonds, E.J., Millard, N.W., McPhail, S.D.,

524 Armstrong, F., Stevenson, P., and Squires, M. 2000. Fish do not avoid survey vessels.

525 Nature, 404: 35-36.

526 Fréon, P., and Misund, A.A. 1999. Dynamic of pelagic fish distribution and behaviour:

527 Effects on fisheries and stock assessment. Fishing News Books, Oxford.

528 Godø, O.R., Somerton, D., and Totland, A. 1999. Fish behaviour during sampling as

529 observed from free floating buoys: Application for bottom trawl survey assessment.

530 ICES-CM-1999/J:10.

531 Godø, O.R., and Michalsen, K. 2000. Migratory behaviour of north-east Arctic cod,

532 studied by the use of data storage tags. Fisheries Research, 48: 127-140.

533 Gunderson, D.R. 1993. Surveys of fisheries resources. John Wiley and Sons, New-York. 
534 Handegard, N.O., Michalsen, K., and Tjøestheim, D. 2003. Avoidance behaviour in cod

535 (Gadus morhua) to a bottom trawling vessel. Aquatic Living Resources, 16: 265-270.

536 Hjellvik, V., Godø, O.R, and Tjøestheim, D. 2002. Diurnal variation in bottom trawl

537 survey catches:. does it pay to adjust? Canadian Journal of Fisheries and Aquatic

538 Sciences, 59: 33-48.

539 Hjellvik, V., Michalsen, K., Aglen, A., and Nakken, O. 2003. An attempt at estimating

540 the effective fishing height of the bottom trawl using acoustic survey recordings. ICES

541 Journal of Marine Science, 60: 967-979.

542 Kloser, R.J., and Horne, J.K. 2003. Characterizing uncertainty in target strength

543 measurements of a deep water fish: orange roughy (Hoplostethus atlanticus). ICES

544 Journal of Marine Science, 60: 516-523.

545 Korsbrekke, K., Mehl, S., Nakken, O., and Pennington, M. 2001. A survey based

546 assessment of the north east arctic cod stock. ICES Journal of Marine Science, 58: 763-

$547 \quad 769$.

548 Krieger, K., Heifetz, J., and Ito, D. 2001. Rockfish assessed acoustically and compared to

549 bottom trawl catch rates. Alaska Fisheries Research Bulletin, 8: 71-77.

550 Lawson, G.L., and Rose, G.A. 1999. The importance of detectability to acoustic surveys

551 of semi-demersal fish. ICES Journal of Marine Science, 56: 370-380.

552 MacLennan, D.N., Magurran, A.E., Pitcher, T.J., and Hollingworth, C.E. 1987.

553 Behavioural determinants of fish target strength. Rapp. P.-V. Réun. CIEM, 189: 245-253.

554 MacLennan, D.N., Fernandes, P.G., and Dalen, J. 2002. A consistent approach to

555 definitions and symbols in fisheries acoustics. ICES Journal of Marine Science, 59:365-

$556 \quad 369$ 
557 McQuinn, I.H., and Winger, P.D. 2003. Tilt angle and target strength: target tracking of

558 Atlantic cod (Gadus morhua) during trawling. ICES Journal of Marine Science, 60: 575559583.

560 Michalsen, K. 1999. Distribution of gadoids in the Barents Sea: impact on survey results.

561 Ph.D. thesis, University of Bergen, Norway.

562 Michalsen, K., Godø, O.R., and Ferno, A. 1996. Dial variation in the catchability of 563 gadoids and its influence on the reliability of abundance indices. ICES Journal of Marine 564 Science, 53: 389-395.

565 Mitson, R.B., and Knudsen, H.P. 2003. Causes and effects of underwater noise on fish 566 abundance estimation. Aquatic Living resources, 16: 255-263.

567 Ona, E., and Mitson, R.B. 1996. Acoustic sampling and signal processing near the 568 seabed: the deadzone revisited. ICES Journal of Marine Science, 53: 677-690.

569 Pedersen, J. 2000. Food consumption and daily feeding periodicity: comparison between 570 pelagic and demersal whiting in the North Sea. Journal of Fish Biology, 57: 402-416.

571 Pillar, S.C., and Barange, M. 1997. Dial variability in bottom trawl catches and feeding 572 activity of the Cape hakes off the west coast of South Africa. ICES Journal of Marine 573 Science, 54: 485-499.

574 Rivoirard J., Simmonds, J., Foote, K., Fernandes, P., and Bez, N. 2000. Geostatistics for 575 estimating fish abundance. Blackwell Science Ltd, Oxford, 206 p. 
579 Figure 1 Study areas (a) and sampling schemes for (b) the International Bottom Trawl 580 surveys (IBTS), (c) the Northern Irish Bottom Trawl Surveys (NIBTS), and (d) the 581 combined acoustic and bottom trawl surveys for cod (Gadus morhua) and haddock

582 (Melanogrammus aeglefinus) in the Barents Sea. Solid squares represent stations. Crosses 583 represent between-station recordings. They appear as lines when the density of between 584 stations observations is large.

586 Figure 2. Bottom-referenced depth layers used for the acoustic integration. The first 10 587 layers from the bottom have a height of $1 \mathrm{~m}$; the following layers are $10 \mathrm{~m}$ in height. 588 Mid-water and bottom layers used for the analysis are represented for the Barents Sea 589 surveys (right) and the North Sea or Irish Sea surveys (left).

591 Figure 3. Vertical profiles of acoustic backscattering. Barents Sea survey (1997-2002). 592 Representation of the 25\% and 75\% quantiles of Nautical Area Scattering Coefficient 593 (NASC) values per layer for on-station data (dashed lines) and between-station data 594 (solid lines).The $\mathrm{x}$-axis is the mean NASC value (in $\mathrm{m}^{2} \cdot \mathrm{n} \cdot \mathrm{mi}^{-2}$ ) per layer. The $\mathrm{y}$-axis is 595 the height of each layer relative to the detected bottom (in meters).

597 Figure 4. Vertical profiles of acoustic backscattering. International Bottom Trawl 598 surveys (IBTS): (a) Fisheries Research Services (FRS), (b) Environment Fisheries and 599 Aquaculture Science (Cefas) and (c) Institut Français de Recherche pour l'Exploitation de 
600 la Mer (Ifremer). Representation of the $25 \%$ and $75 \%$ quantiles of Nautical Area 601 Scattering Coefficient (NASC) values per layer for on-station data (dashed lines) and 602 between-station data (solid lines).The $\mathrm{x}$-axis is the mean NASC value (in $\mathrm{m}^{2} \cdot \mathrm{n} \cdot \mathrm{mi}^{-2}$ ) per 603 layer. The y-axis is the height of each layer relative to the detected bottom (in meters).

605 Figure 5 Vertical profiles of acoustic backscattering. Northern Irish Bottom Trawl 606 Surveys (NIBTS) without pelagic data. Representation of the $25 \%$ and $75 \%$ quantiles of 607 Nautical Area Scattering Coefficient (NASC) values per layer for on-station data (dashed 608 lines) and between-station data (solid lines).The $\mathrm{x}$-axis is the mean NASC value (in

$609 \mathrm{~m}^{2} \cdot n \cdot \mathrm{mi}^{-2}$ ) per layer. The y-axis is the height of each layer relative to the detected bottom 610 (in meters).

611

612 Figure 6 Histogram of Global Indices of Collocations (GICs) between on-station and 613 between-station spatial distributions of Nautical Area Scattering Coefficient (NASC) 614 values. All surveys combined. Distinction between bottom layers (i.e. GIC $_{0-40}$ for the 615 Barents Sea surveys and $G I C_{0-10}$ for the others) and mid-water layers (i.e. GIC $_{40-100}$ for 616 the Barents Sea surveys and $G I C_{10-40}$ for the others).

618 Figure 7 Variograms of log-transformed Nautical Area Scattering Coefficient (NASC). 619 Average of normalised variograms per series of surveys. (a) Barents Sea Surveys 1997620 2002. International Bottom Trawl surveys (IBTS): (b) Fisheries Research Services (FRS),

621 (c) Environment Fisheries and Aquaculture Science (Cefas) and (d) Institut Français de 622 Recherche pour l'Exploitation de la Mer (Ifremer). (e) Northern Irish Bottom Trawl 
623 Surveys (NIBTS). Solid lines: between-station variograms. Dashed lines: on-station

624 variograms. Omni directional computations. Distance lags are the ESDU for between-

625 station NASC and the inter stations distance for the on station NASC. The quantile of

626 active data is indicated ( $98 \%$ means that the most extreme $2 \%$ of the data was removed).

628 Figure 8 Difference between the vertically integrated Nautical Area Scattering 629 Coefficient (NASC) observed before, during and after trawling ( $\nabla$ during - before and $\Delta$ 630 during - after) and for two randomly selected successive between station observations

631 ( $\square$ ). The mean difference is indicated by the symbols and cumulative distribution of the 632 differences is indicated by the lines. Each panel represents the pooled data for each

633 survey series. The $\mathrm{x}$-axis represents relative differences of NASC in $\mathrm{m}^{2} \cdot n \cdot \mathrm{mi}^{-2}$. The $\mathrm{y}-$ 634 axis represents the empirical cumulative density function. Distinction is made between 635 mid water layers (a) and bottom layers (b). P-values of the Student tests are indicated: 636 solid symbols represent values smaller than 0.1 .

637

638 Figure 9 Difference between the altitude of the centre of mass of the Nautical Area 639 Scattering Coefficient (NASC) values observed before, during and after trawling ( $\nabla$ 640 during - before and $\Delta$ during - after), and for two randomly selected successive between 641 station observations ( $\square$ ).The mean difference is indicated by the symbols and cumulative 642 distribution of the differences is indicated by the lines. Each panel represents the pooled 643 data for each survey series. The x-axis represents relative differences of NASC in $644 \mathrm{~m}^{2} \cdot n \cdot \mathrm{mi}^{-2}$. The y-axis represents the empirical cumulative density function. Distinction is 
645 made between mid water layers (a) and bottom layers (b). P-values of the Student tests

646 are indicated: solid symbols represent values smaller than 0.1 .

647

648 Figure 10 Global Indices of Collocations (GICs) for simulated situations. Fish 649 distributions are considered to be isotropic and distributed according to a Gaussian 650 distribution with fish density being set to zero for densities below the quantile 5\%. Two

651 types of fish populations are concerned (patchy or spread). Several possible distances 652 between the centres of mass are concerned.

653

654 Figure 11 Scale representation of the observation protocol. North Sea and Irish Sea 655 survey protocols are not distinguished.

656 
(a)
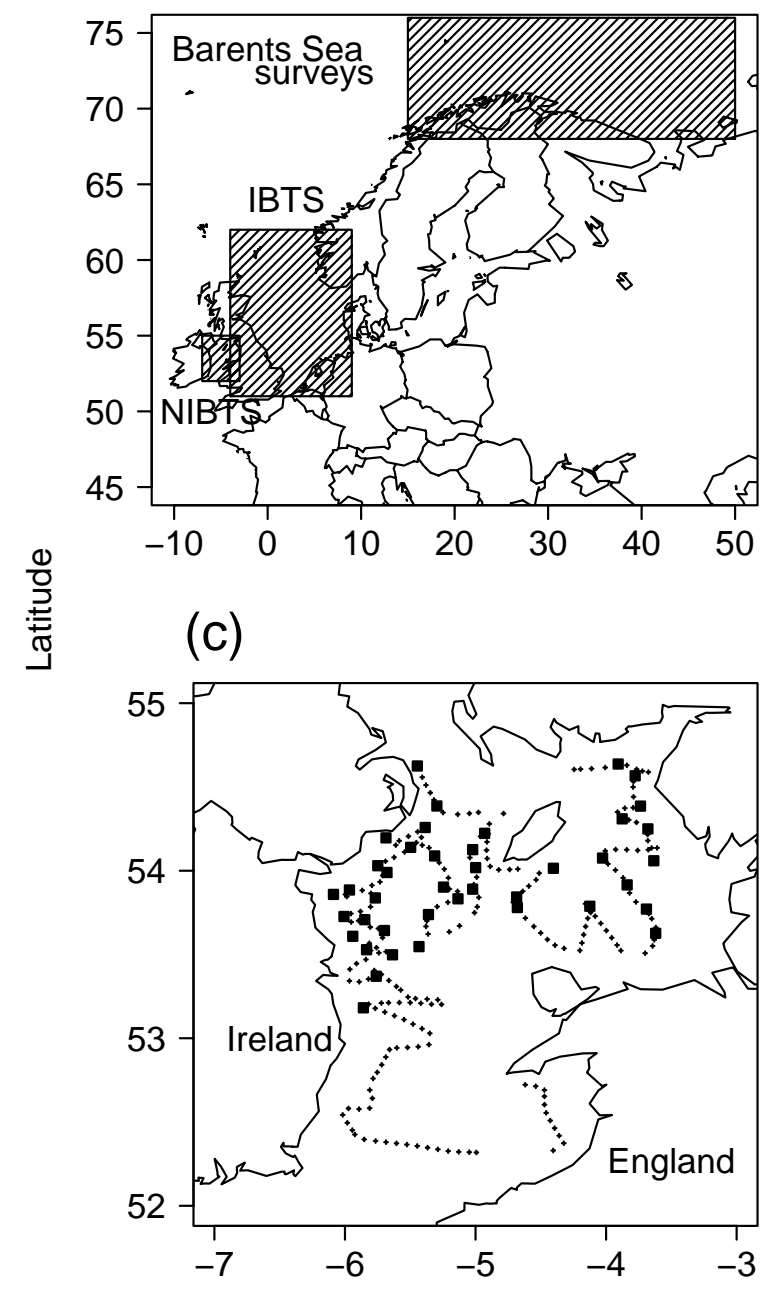

(b)

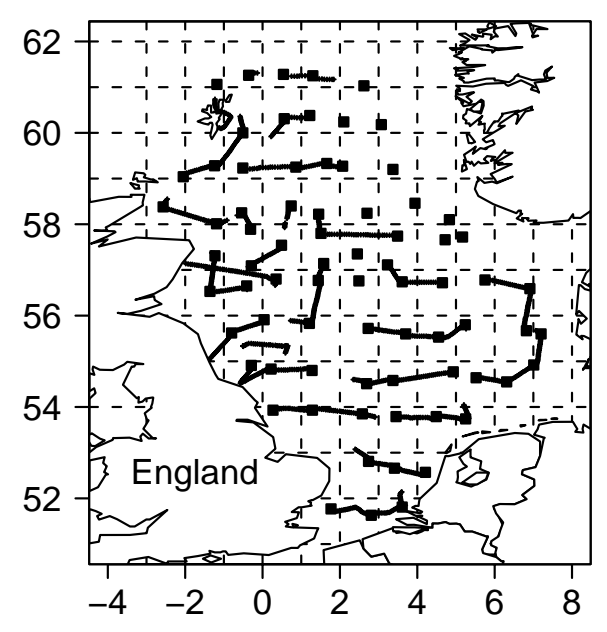

(d)

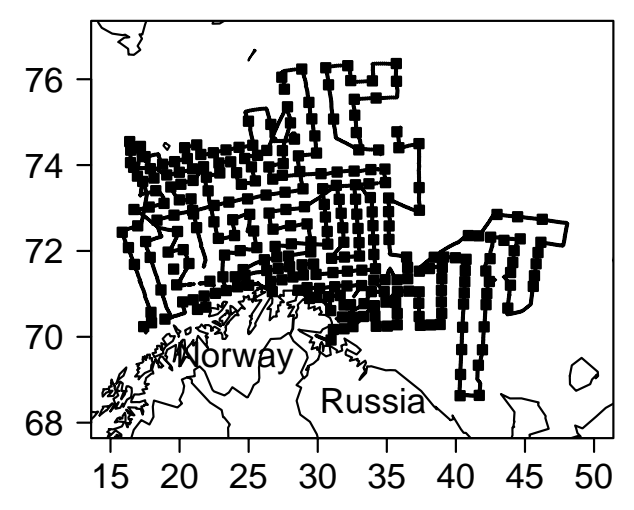

657

Longitude

658

659 


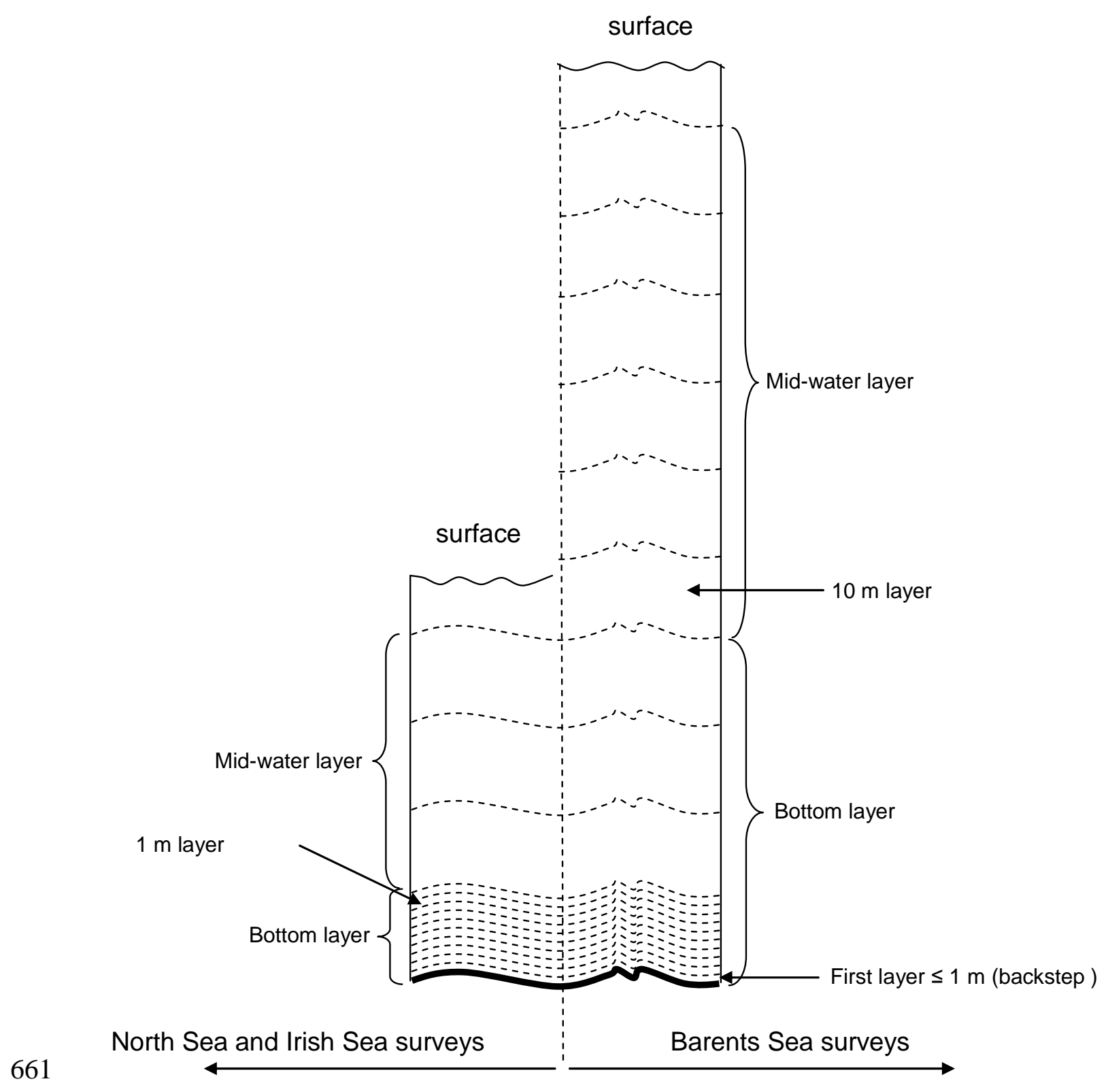

662

663 

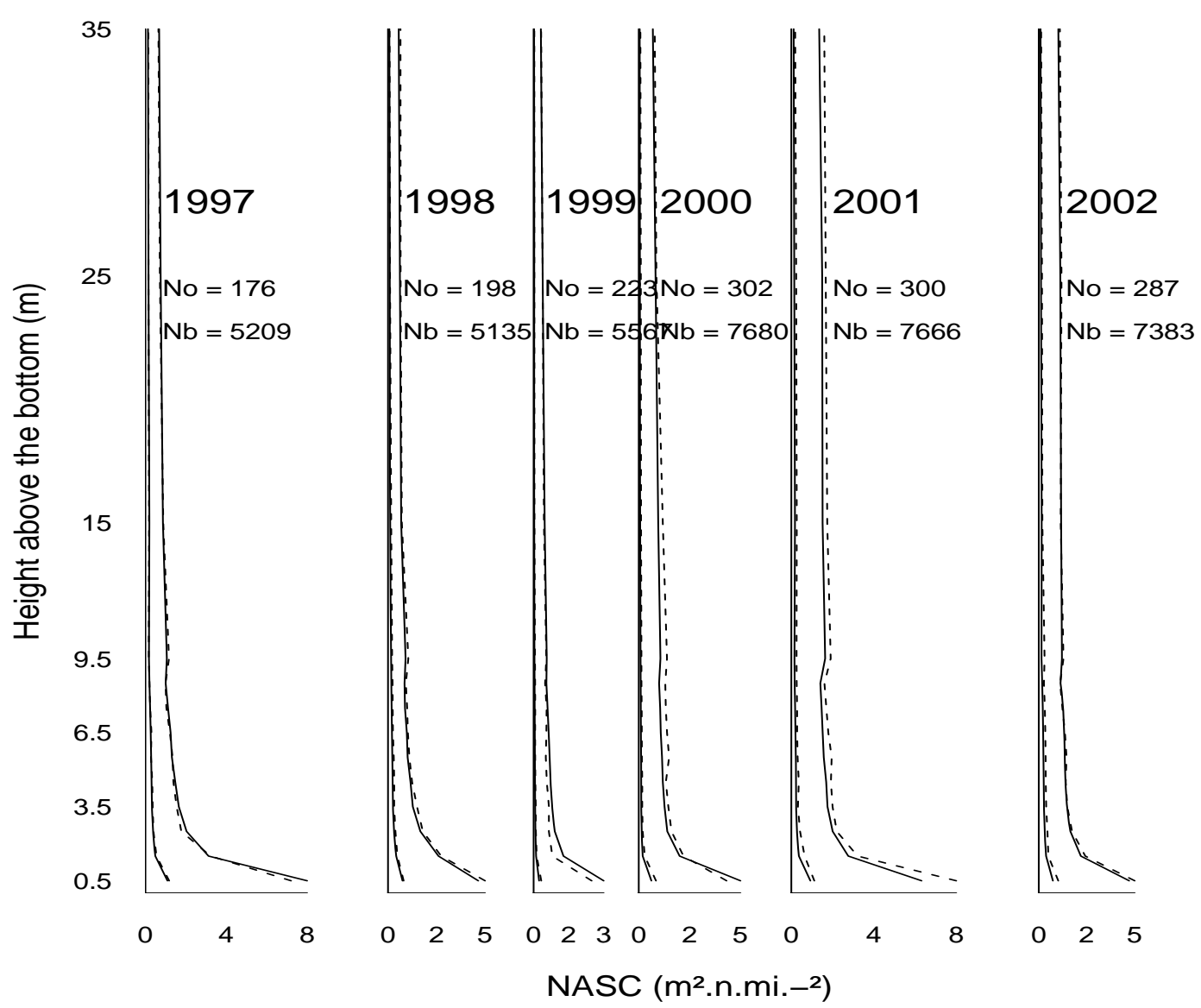
(a)

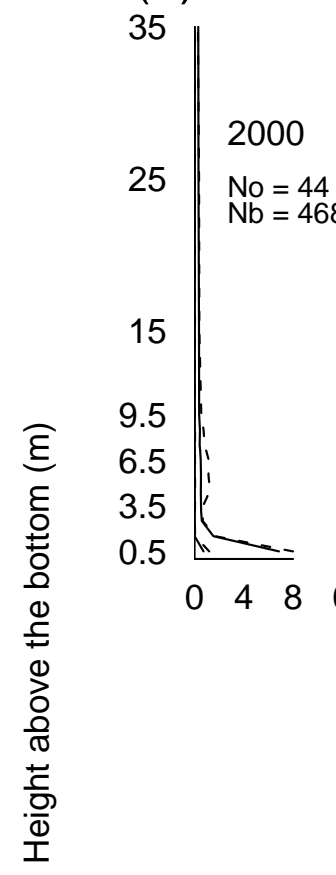

(b)

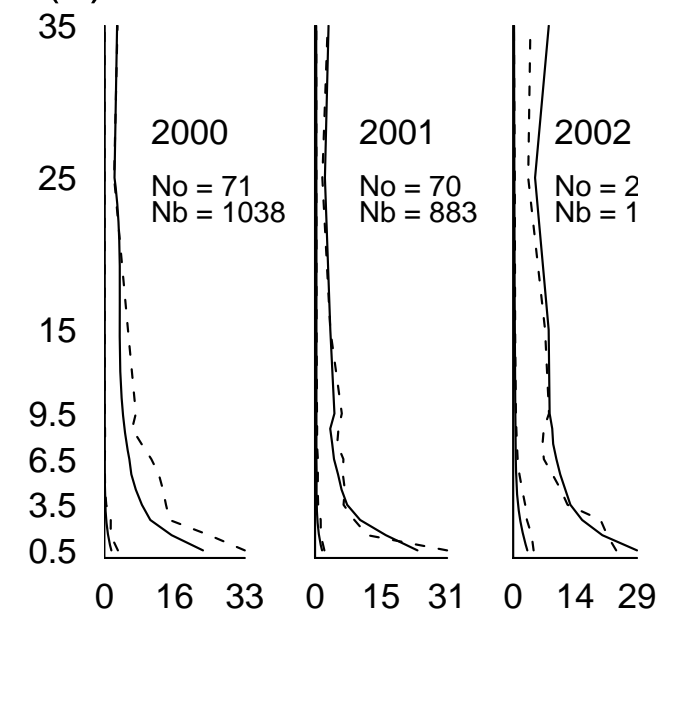

668

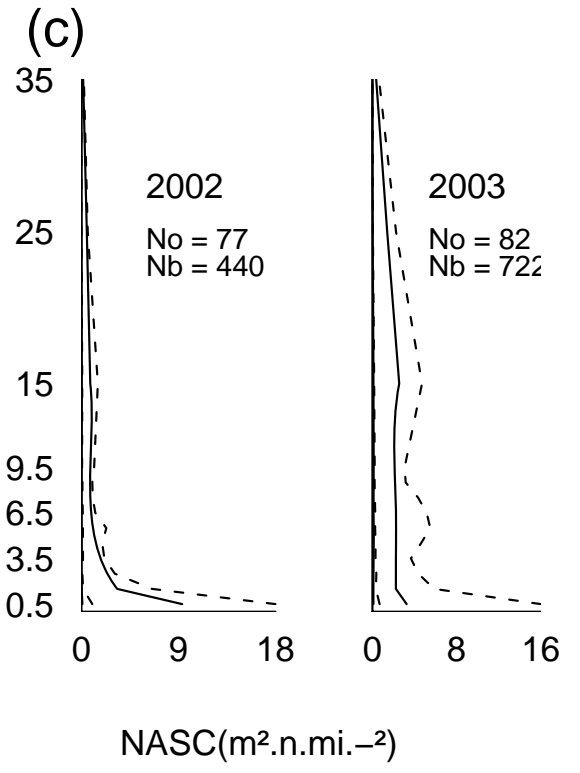

669 


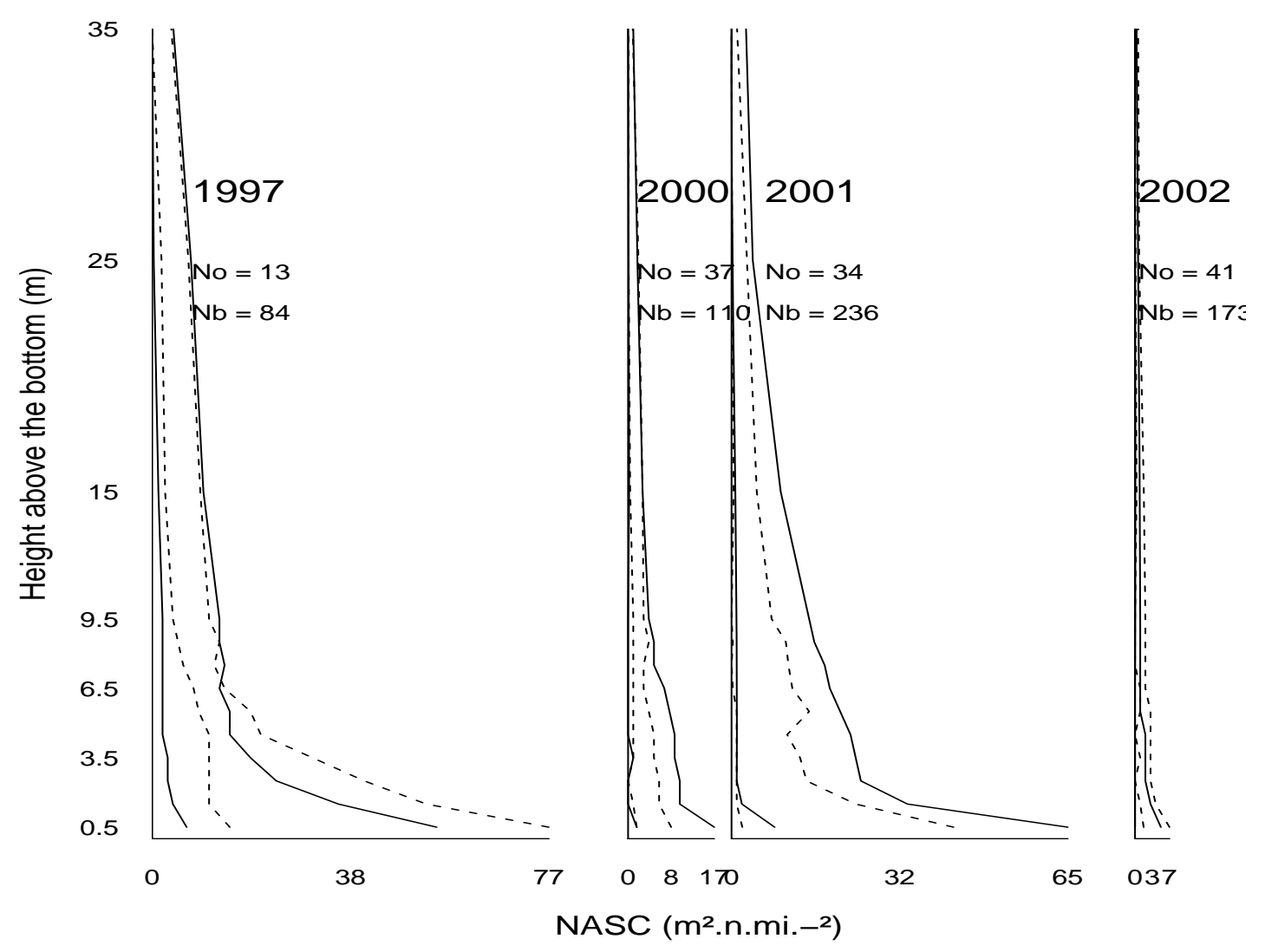


672

673

674

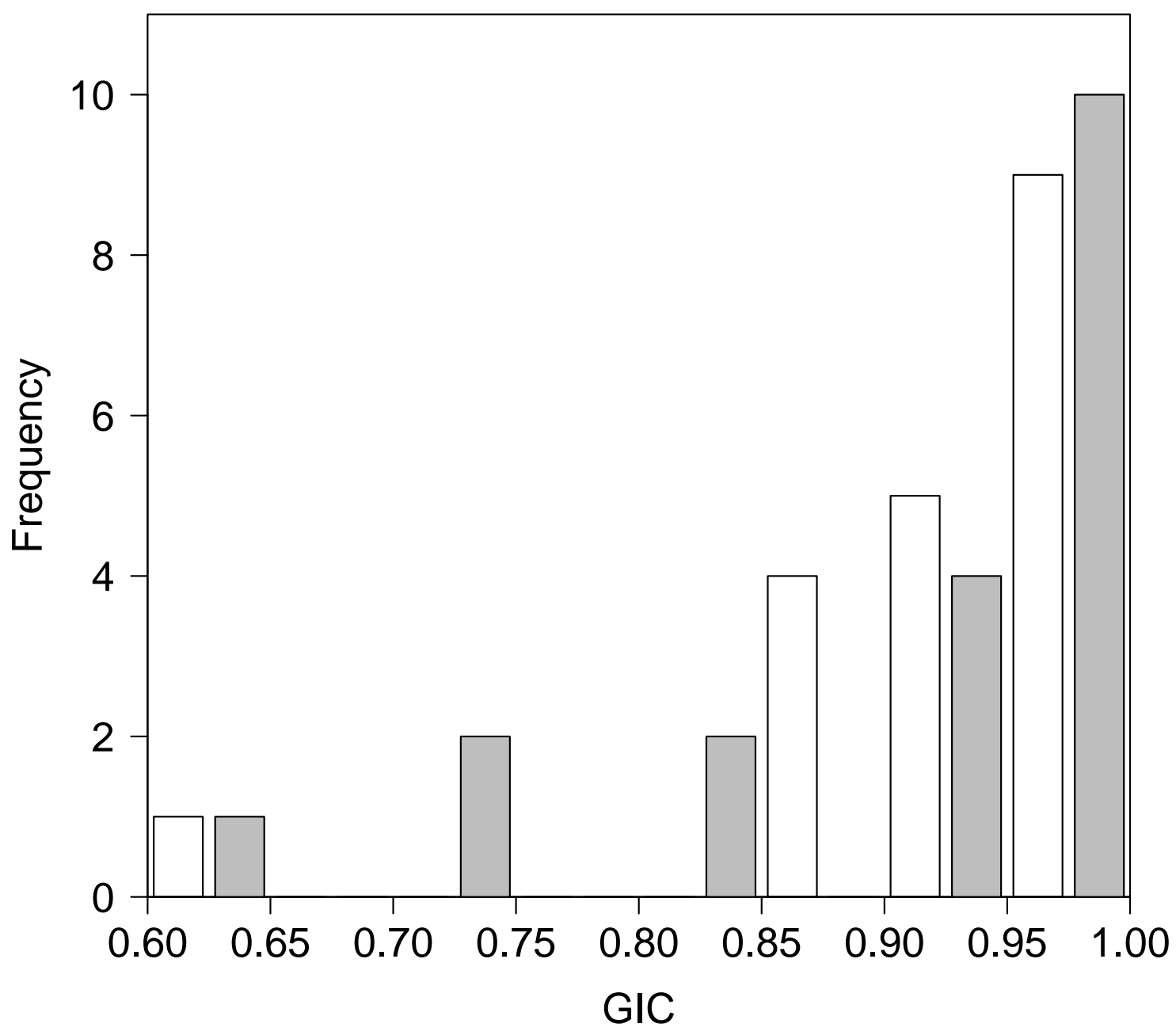

675

676

677 
(a)

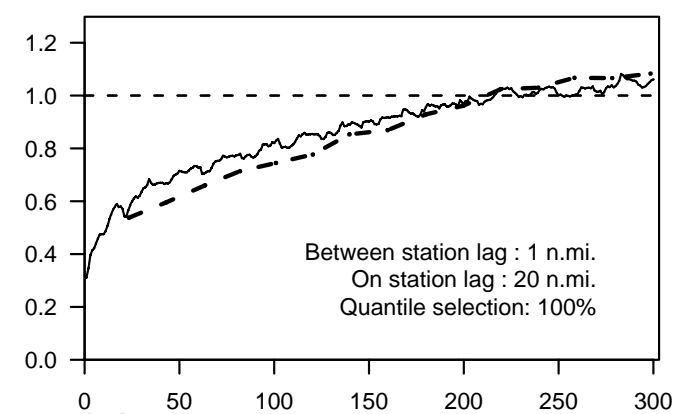

(c)

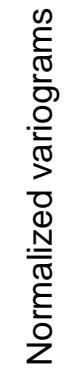

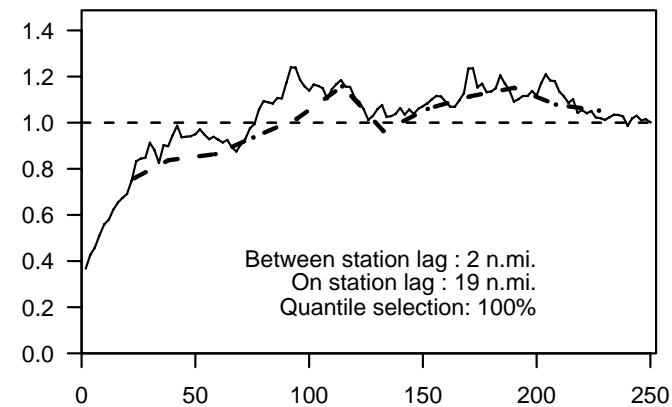

(e)
(D)

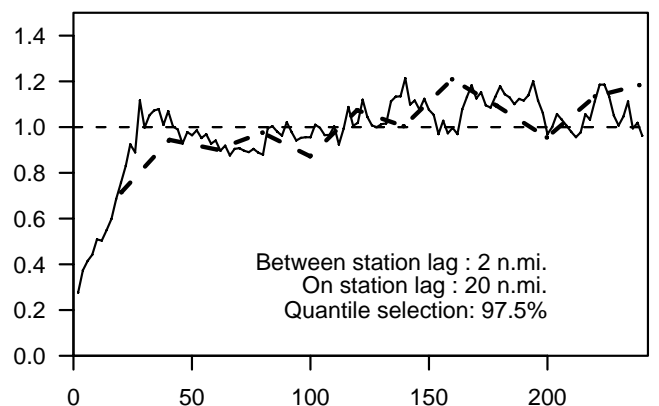

(d)

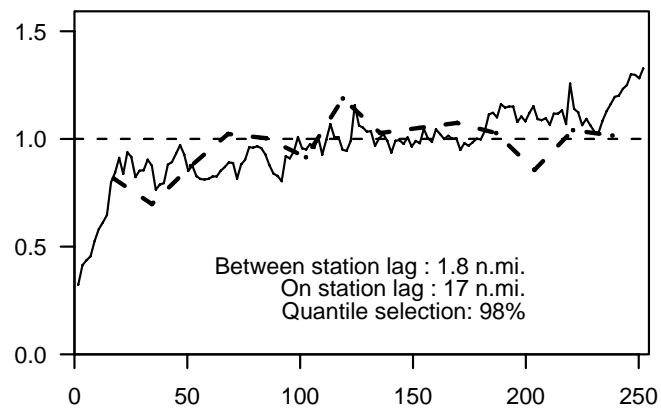

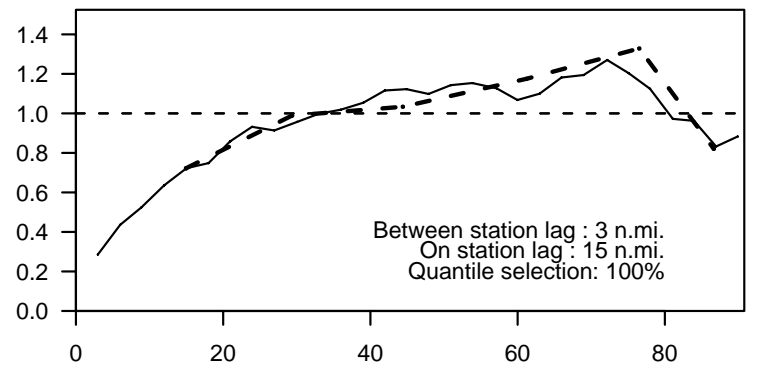

679

Distance(n.mi.) 


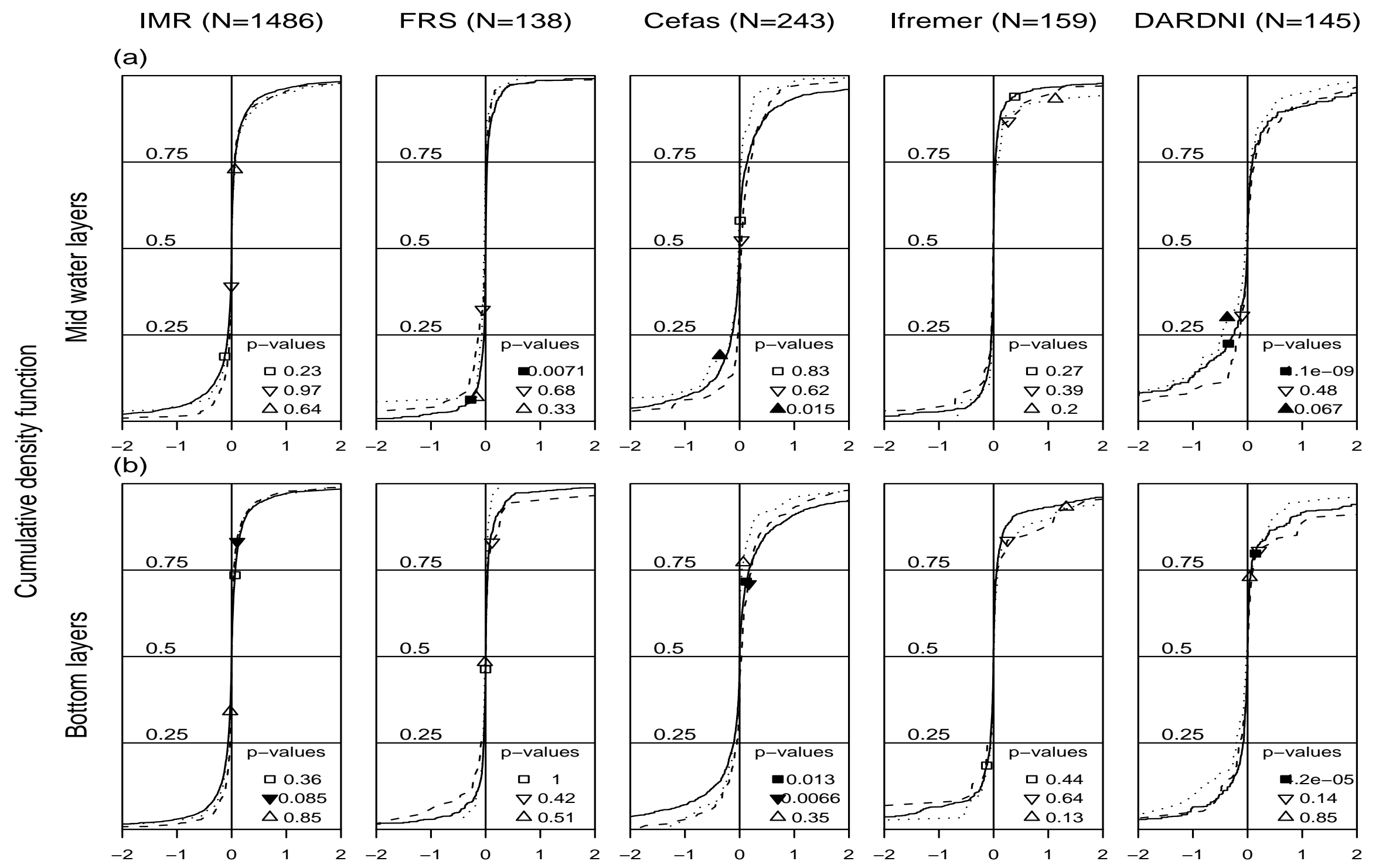

Relative NASC difference 


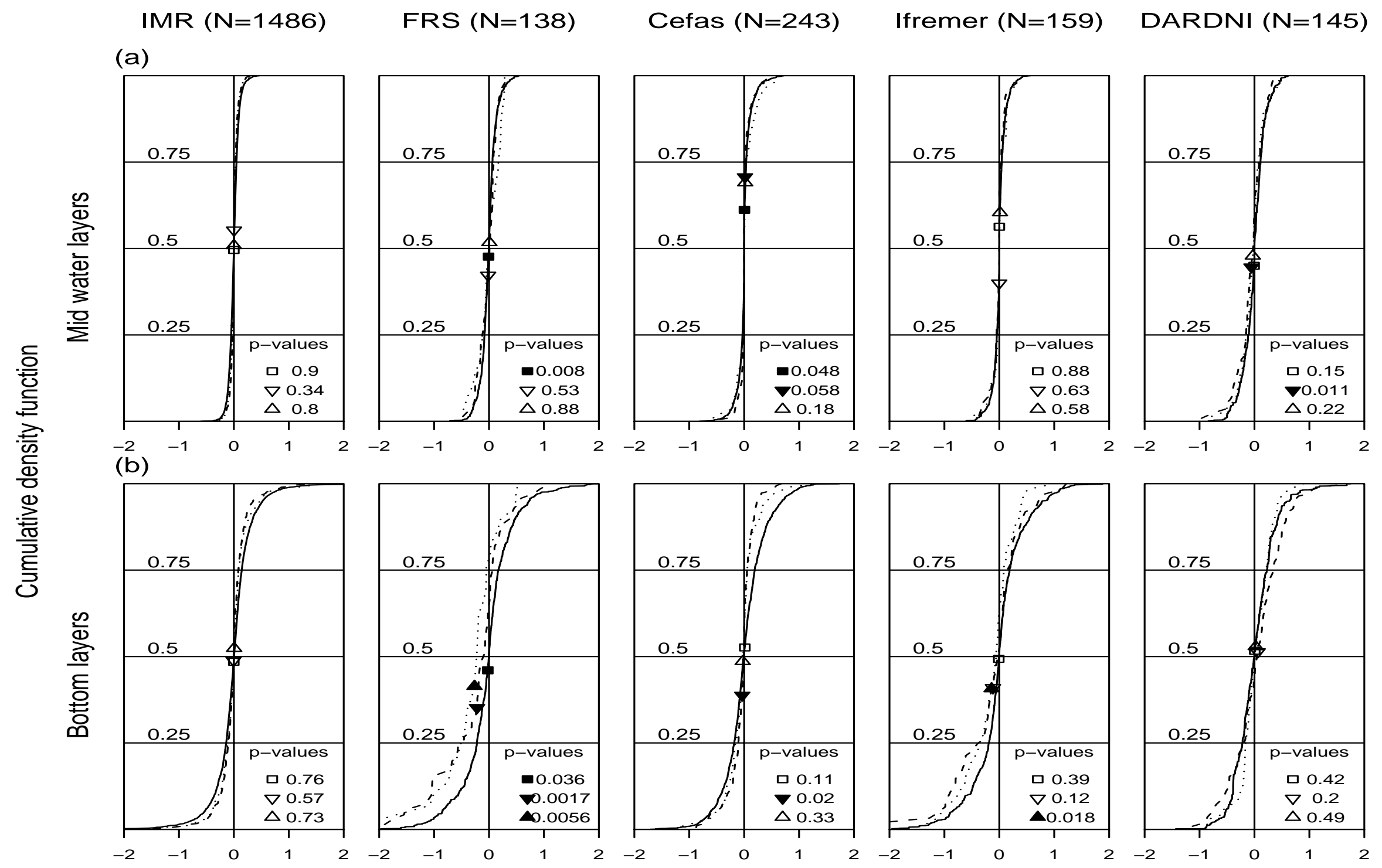

Relative height difference 

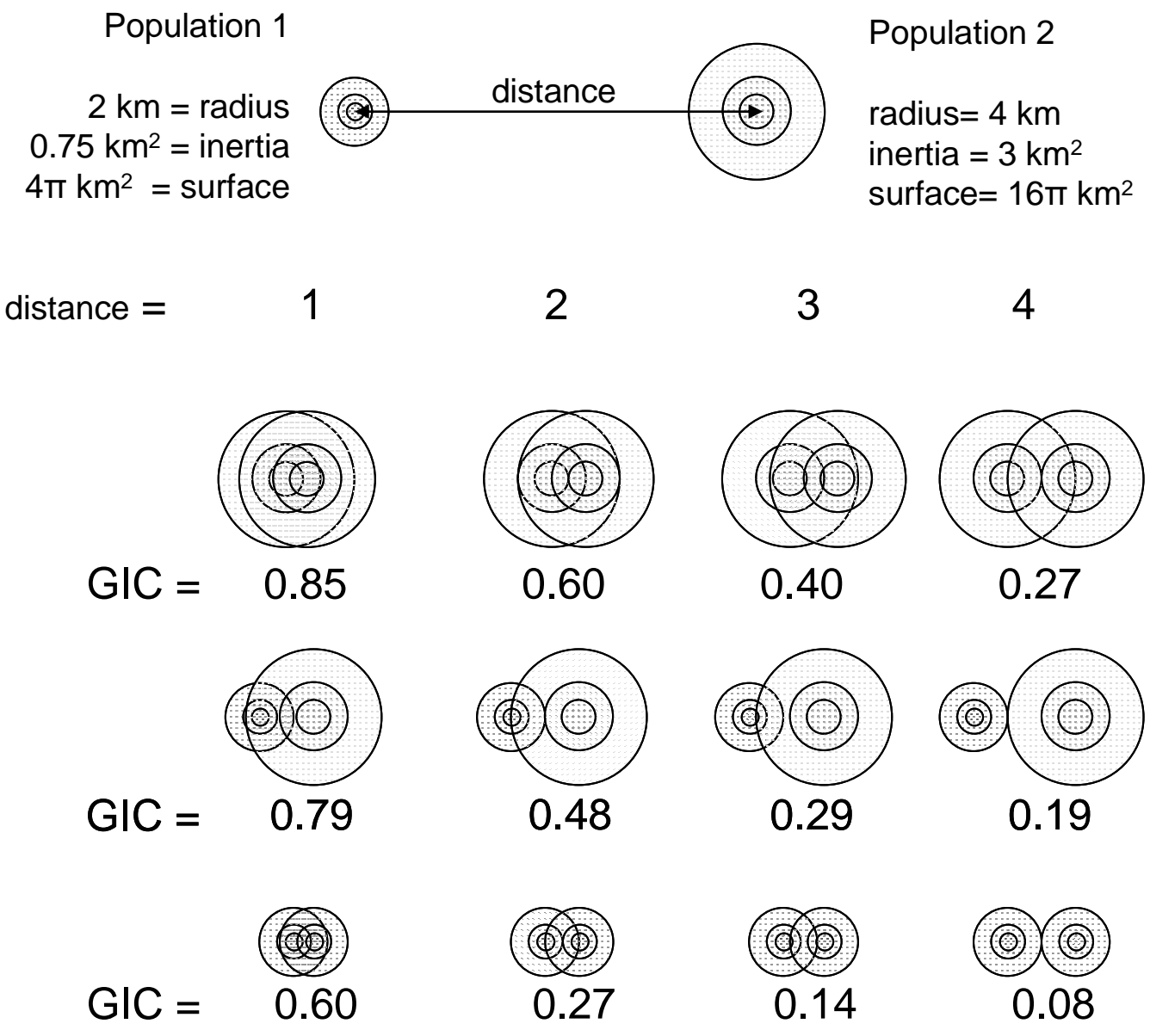


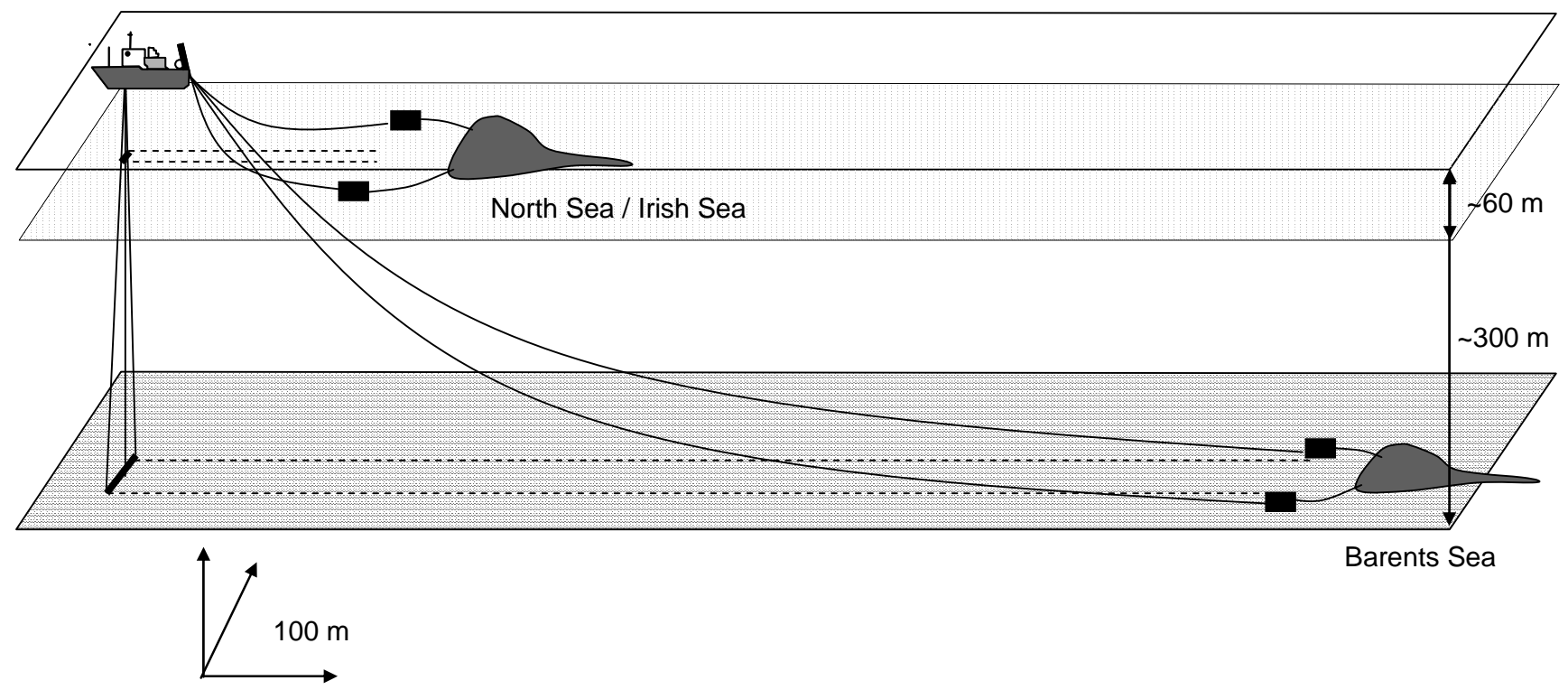


Table 1. Main characteristics of the various surveys used in the analyses. ESDU : Elementary Sampling Distance Unit

\begin{tabular}{|c|c|c|c|c|c|c|c|c|c|c|c|}
\hline \multirow[t]{2}{*}{ Area } & Survey & year & month & \multirow[t]{2}{*}{ stations } & $\begin{array}{l}\text { Mean } \\
\text { towed distance }\end{array}$ & Original & $\begin{array}{c}\text { Number of } \\
\text { between station data }\end{array}$ & $\begin{array}{l}\text { Height used to } \\
\text { split vertical }\end{array}$ & \multirow[t]{2}{*}{ (m) } & $\begin{array}{c}\text { GIC } \\
\text { "bottom” }\end{array}$ & $\begin{array}{c}\text { GIC } \\
\text { "midwater" }\end{array}$ \\
\hline & series & & & & (n.mi.) & (in n.mi.) & (after regularization) & profiles & & layers & layers \\
\hline \multirow{3}{*}{ Barents } & IMR & \multicolumn{2}{|c|}{1997 02- 03} & 176 & 1.50 & 1 & 5209 & 40 & $143-699$ & 0.98 & 0.95 \\
\hline & IMR & 1998 & 02 & 198 & 1.53 & 1 & 5135 & 40 & $63-720$ & 0.9 & 0.85 \\
\hline & IMR & 1999 & 01- 02 & 223 & 1.49 & 1 & 5567 & 40 & $104-480$ & 0.99 & 0.97 \\
\hline \multirow[t]{6}{*}{ Sea } & IMR & 2000 & 01- 02 & 302 & 1.42 & 1 & 7680 & 40 & $58-550$ & 0.98 & 0.99 \\
\hline & IMR & 2001 & 01- 03 & 300 & 1.49 & 1 & 7666 & 40 & $55-487$ & 0.97 & 0.96 \\
\hline & IMR & 2002 & 01- 03 & 287 & 1.44 & 1 & 7383 & 40 & $63-542$ & 0.98 & 0.98 \\
\hline & FRS & 2000 & 01- 02 & 44 & 1.8 & 0.5 & 468 & 10 & $45-150$ & 0.6 & 1 \\
\hline & FRS & 2002 & 01- 02 & 46 & 2.01 & 0.5 & 351 & 10 & $48-144$ & 0.89 & 0.74 \\
\hline & FRS & 2003 & 01- 02 & 47 & 1.98 & 0.5 & 430 & 10 & $49-150$ & 0.9 & 0.98 \\
\hline \multirow[t]{6}{*}{ North Sea } & Cefas & 2000 & $08-09$ & 71 & 1.98 & 0.5 & 1038 & 10 & $24-178$ & 0.99 & 0.99 \\
\hline & Cefas & 2001 & $08-09$ & 70 & 2.01 & 0.5 & 883 & 10 & $24-211$ & 0.99 & 0.84 \\
\hline & Cefas & 2002 & 02 & 23 & 1.98 & 0.5 & 1140 & 10 & $24-84$ & 0.93 & 0.97 \\
\hline & Ifremer & 2002 & 02 & 77 & 1.83 & 0.1 & 440 & 10 & $9-88$ & 0.9 & 0.95 \\
\hline & Ifremer & 2003 & 02 & 82 & 1.89 & 0.1 & 722 & 10 & $14-90$ & 0.93 & 0.75 \\
\hline & DARDNI & 1997 & 10 & 13 & 3.00 & 0.5 & 84 & 10 & $25-103$ & 0.98 & 0.91 \\
\hline \multirow[t]{3}{*}{ Irish Sea } & DARDNI & 2000 & 3 & 37 & 2.90 & 0.5 & 110 & 10 & $26-106$ & 0.99 & 0.95 \\
\hline & DARDNI & 2001 & 10 & 34 & 2.70 & 0.5 & 236 & 10 & $23-90$ & 0.94 & 0.99 \\
\hline & DARDNI & 2002 & 3 & 41 & 2.85 & 0.5 & 173 & 10 & $24-102$ & 0.93 & 0.98 \\
\hline
\end{tabular}


